\title{
Learning Lab "Digital Technologies" - Concept, Streams and Experiences
}

\section{Brehm, Lars and Guenzel, Holger}

Department of Business Administration, Munich University of Applied Sciences, Germany

\begin{abstract}
Digital technology capabilities are highly important also for non-computerscience students. Unfortunately, the understanding of the underlying technologies of daily used devices is often non-existent, but also difficult for lecturers to explain. There is a need for new ways of teaching and learning; this here presented concept of the Learning Lab "Digital Technologies" is an answer to this challenge for building up knowledge and breaking down barriers to technology in a playful and self-contained way. The focus is on hands-on approaches to technology and solving assignments in small student teams.

The four core elements of the Learning Lab: didactic concept, stream concept, assignment repository concept and community concept. The article outlines the experiences with students of the business administration master program in the specialisation field of "Digital Technology Entrepreneurship" at the Munich University of Applied Sciences. The article concludes with all key benefits of the Learning Lab for students and lecturers and an outlook for further development.
\end{abstract}

Keywords: Learning Lab, Digital Capabilities, Digital Technology 


\section{Introduction}

The usage of smartphones and tablets by students is taken for granted; on the other hand non-computer-science students understanding of the utilised technologies with their strengths, weaknesses and the related risks by on the other hand is often less significant. Especially in the era of digitization, academic teaching needs to give students an understanding of digital competencies as well. Beside the discussed effects of digitalization on collaborative skills, these include communication skills, project management and selflearning competence by Kreulich and Dellmann (2016), especially the understanding of digital technologies and digital systems architectures.

For students of the business administration master program in the specialisation field of "Digital Technology Entrepreneurship" at the Munich University of Applied Sciences (http://t1p.de/DTE), the topic "digital technologies" - especially the architectures of IT systems and their business impact analysis as well as innovation drivers, like Internet of things (IoT), big data or Virtual Reality / Augmented Reality - is an important curricular element. The challenges of the master program sometimes lie in the distance of the students to their educational background, but also in inflexible learning spaces (especially computer pools) not designed for collaborative work.

Therefore, the authors of this article searched for solutions for the following questions: What is necessary for a good Learning Lab to "properly" put digital technologies to the test? How can a playful, self-controlled start with "self-learning methods" be realized at moderate costs?

\section{Fundamentals of the Learning Lab}

The Learning Lab "Digital Technologies" serves as a new approach, in which students can, through concrete sample projects, familiarise themselves with digital technology and its possibilities - without becoming "too technical". This foundation is the basis for applications in areas like data mining, industrial internet or smart mobility. The Learning Lab includes four core elements: didactic concept, stream concept, assignment repository concept and community concept.

\subsection{Didactic concept}

"Competence-building and maturing learning is a self-directed action through which the learning subject develops abilities regarding self-organised and proper problem-solving. It moves inside a learning environment (that defines a competence profile and distribution methods), but simultaneously realises a learning inner world (self-learning and design)" (Arnold \& Erpenbeck, 2014, p. 5 f.). The didactic requirements for that are: from input to infrastructure, the opening of a subject classification system to situation dynamics and from instruction to self-directed learning (Arnold \& Erpenbeck, 2014). Therefore, the change of 
perspective from a knowledge-delivering didactic to a self-controlled acquisition of knowledge and competencies is fundamental (Blinkstein 2013). This is based on the insight that learning is most effective when the learner can acquire the findings independently, experience their sustainability and is able to put them to the test (Schüßler, 2008). In such a context the didactic setting (the learning infrastructure) holds a distinguished position. Like in a physical workshop the Learning Lab calls for diverse materials and tools that encourage self-active learning and learning through experience. Frontal-arranged seminar rooms with fixed furniture and without appropriate teaching and learning materials are unsuitable for this purpose. The Learning Lab focuses on designing inspiring learning environments and learning situations.

In the classic definition of self-directed learning, Knowles (1975, p. 18) describes the approach of self-directed learning as "a process in which individuals take the initiative, with or without the help of others, in diagnosing their learning needs, formulating their learning goals, identifying human and material resources for learning, choosing and implementing appropriate learning strategies, and evaluating learning outcomes“".

It is necessary to especially highlight that built into the process of self-directed learning is a constant reflection and hence, correction loop through the evaluation aspect. Within the learning process the teacher plays different roles. He or she is an expert for the learning content, active listener, productive inquiring person, enabler for a focused and trusting learning atmosphere, trainer that recommends exercises, and process facilitator in the sense of a "critical friend" (Siebert, 2009; Borthick, Jones, \& Wakai, 2003).

In the Learning Lab, student teams are being challenged to use hard- and software through the autonomous work on exercises or small sample projects, the so-called assignments; quick wins motivate the students to independently deal with and solve following exercises. The lecturers are predominantly there as coaches. The assignments are concluded by reflection work and "lessons learned" elements. To carry the course through, the Learning $\mathrm{Lab}$ is temporarily set up in a seminar room with flexible furniture.

\subsection{Stream concept}

The Learning Lab is geared to offer several streams. An overview of the currently available streams is shown in figure 1. Additional streams can be added easily.

All streams are based on the utilisation of available, inexpensive and expandable standard components. We used the following digital technologies:

- Digital Technologies Essentials: The Raspberry Pi3 with memory card, power supply, monitor cable as well as various sensors and actuators - such as the "Sense-Hat" to measure temperature and motion as well as an LED field - meet these requirements with a maximal total amount of 100 euros per team. The 
introductory assignments require a keyboard with a mouse and a monitor, which were taken from the department's inventory. In terms of software, the free-ofcharge operating system Raspbian and freely available software packages - like the programming language Python - are used.

- Learn to Code with Cozmo: To use the robot Cozmo (www.anki.com), the students need a tablet (Android or IOS) and a cost-free app for using the programming language Scratch or additionally a computer and a simple editor to get deeper into the use of sensors and actuators with Python. With Scratch, the participants can make a practical introduction to programming constructs like loops or variables and robotics elements like driving or lifting a cube.

- 360 VR Collaboraton: The students use end-consumer 360 degree video cameras as well as Virtual Reality glasses (based on Android smartphones and Samsung VR gear headset). In the stream they understand the technology, produce $360^{\circ}$ videos (at typical locations of our city) and watch them. Additionally, this is embedded in an international project cooperation across three universities. The student teams across the location also watch the presentation of the other locations and thus share not only the content, but also some part of their surroundings.

\begin{tabular}{|c|c|c|}
\hline $\begin{array}{l}\text { Digital Technologies } \\
\text { Essentials (DTE) }\end{array}$ & $\begin{array}{l}\text { Learn to Code with } \\
\text { Cozmo (LC2) }\end{array}$ & $\begin{array}{l}360^{\circ} \text { Virtual Reality } \\
\text { Collaboration (360VR) }\end{array}$ \\
\hline $\begin{array}{l}\text { Understand digital } \\
\text { architectures }\end{array}$ & $\begin{array}{l}\text { Learn programming \& } \\
\text { robotic basics }\end{array}$ & $\begin{array}{l}\text { Understand virtual } \\
\text { reality }\end{array}$ \\
\hline & & \\
\hline $\begin{array}{c}\text { Raspberry PI } 3 \\
\text { SenseHat }\end{array}$ & $\begin{array}{c}\text { Cozmo } \\
\text { Scratch and Python }\end{array}$ & $\begin{array}{c}\text { Gear } 360^{\circ} \text { camera } \\
\text { VR Glasses }\end{array}$ \\
\hline $\begin{array}{c}2 \text { days } \\
23 \text { assignments }\end{array}$ & $\begin{array}{c}1 \text { or } 2 \text { days } \\
11 \text { or } 22 \text { assignments }\end{array}$ & $\begin{array}{c}1 \text { day } \\
12 \text { assignments }\end{array}$ \\
\hline IoT, database, cloud & ... agile development & ... international project \\
\hline
\end{tabular}

Figure 1: Current streams of the Learning Lab "Digital Technologies"

\subsection{Assignment repository concept}

Derived from the didactic concept a repository with standardised assignments has been created. From a professional perspective, the challenge in creating these assignments is the 
right length and autonomy, so that these assignments can be re-used in different teaching contexts without a complete and elaborate edit becoming necessary. For this reason, a common structure and a consistent composition have been determined:

- title

- learning objectives

- necessary requirements of software and hardware

- solution steps including indications of further information sources and solution hints as well as

- questions about lessons learned in form of a retrospective

Currently the existing 55 assignments of the Learning Lab have a length of between two and twelve pages. The structure allows for assignments with different levels of difficulty and assignment types, from theoretical basics to game manuals, because the detailing of solution steps and solution hints can be varied.

Organisationally and technically these assignments are managed centrally via GitLab. The assignments have been written in the programming language Markdown, to keep them easily edible in a default structure and consistent format within the writing process, despite the distributed creation by the lecturers. In contrast to Markup languages like HTML, explicit formatting commands are not required. The vocabulary is rather small and easy to acquire. From this repository, specific workshop packages for various learning scenarios can be put together with little effort.

\subsection{Community concept}

The Learning Lab's concept also includes the active creation of a community of lecturers, that develops the Learning Lab content-wise as well as technically and also gives access to numerous students coming from different study areas. In addition to universally usable basic modules, subject-specific modules are being developed.

The community includes professorial colleagues at the Munich University of Applied Sciences who face a similar challenge across different departments as well as an interuniversity community across Germany and Europe. Benefits for the colleagues are: a finished and tested didactic concept, small preparation time and - if required - fast adaptability. At the same time the Learning Lab "Digital Technologies" serves as an "umbrella brand" to develop new formats like Internet of things (IoT), Machine Learning or Hackathon. 


\section{Experiences}

In the following we describe the experiences with the Learning Lab "Digital Technologies Essentials", which have been performed three times in the last two semesters. It has the following structure of two workshop sessions and a preparatory introduction (see figure 2).
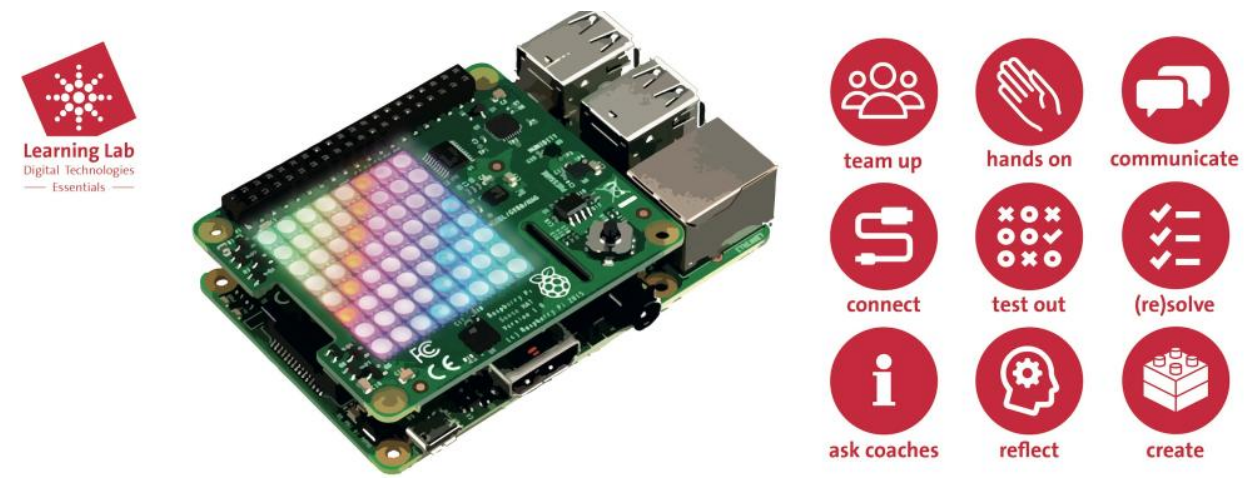

hands on

communicate
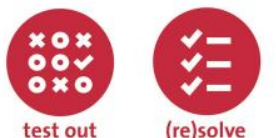

test out

(re)solve
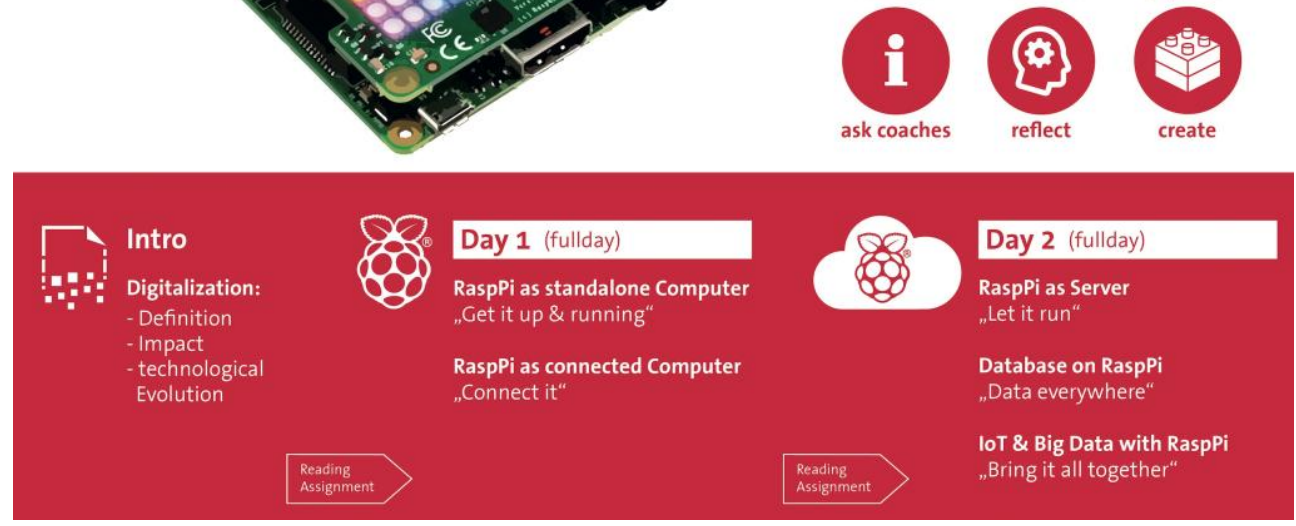

Figure 2: Overview of the Learning Lab "Digital Technologies Essentials".

The Learning Lab "Digital Technologies Essentials" was designed, set up and carried out within several weeks. The starting point was the concept including two workshop days preceded by an introduction to the theoretical basics and several texts for self-study. The first workshop day serves as an introduction to hardware, software and the operating system; the second workshop day focusses on the specialist subjects as a basis for the corresponding course. Typical courses are a course on technologies and their architectures, agile project management or a data mining course. In these courses the gained experiencee are taken up again and deepened in the specific direction.

The preparation of the mobile lab included the acquisition of hardware and software (operating system, programming environment, etc.). Also, the selection and development of the theoretical principles as well as the assignments, which were designed separately and tested on the hardware, had to be prepared.

The implementation began within the first weeks of the semester by a three-hour introduction in a face-to-face lecture and a following distribution of the self-learning 
documents. After that, in week two and three, the two all-day workshops were carried through. The students were provided with printouts of the assignments on the workshop days. In this way the independent and intensive engagement in the assignments at a respective own pace is achieved. Paper-based assignment documents also allow for quick notes about own findings. The physical installation of the hardware took place on the workshop days within about one hour before the beginning of the event. The flexible furniture of the room, regarding the creation of autonomous work stations and the possibility to display the workgroup's reflections, is an important factor. The assignments are processed by the students in a mostly autonomous fashion.

From a didactical point of view the experience shows, that the Learning Lab's working method brings along a certain fun factor and motivation for the students, because besides the casual interaction with the topic it allows a self-directed learning at their individual pace. Furthermore, the autonomous group work showed a positive effect. From an organisational point of view the easy acquisition, the high cost-effectiveness and the quick reutilisation in different contexts need to be mentioned. Access to the university WiFi had proved to be unstable during the implementation and will be reviewed.

Overall we have experienced the following key benefits of the learning lab for students and lecturer:

Table 1. Key Benefits of the Learning Lab for Students and Lecturer

\begin{tabular}{|c|c|}
\hline Students & Lecturers \\
\hline $\begin{array}{l}\text { - Reduction of fear of contact with } \\
\text { technology, the subject of computer } \\
\text { science or programming languages } \\
\text { - Development of a basic understanding } \\
\text { for IT architecture, basics of } \\
\text { programming languages, new } \\
\text { technologies such as IoT, cloud, } \\
\text { sensors, robotics, etc } \\
\text { - Raising the awareness of problems } \\
\text { with IT: data security, programming } \\
\text { errors, communication with the IT } \\
\text { department, requirements for } \\
\text { applications, challenges of new } \\
\text { technologies } \\
\text { - Self-determined learning: learners } \\
\text { determine the speed of the unit }\end{array}$ & $\begin{array}{l}\text { Role of a coach: the lecturer acts as a } \\
\text { coach and facilitates the learning } \\
\text { process of the students. During that } \\
\text { process the students determine the } \\
\text { speed of the lecture. } \\
\text { - Establishment of a homogeneous } \\
\text { learning group: Homogenisation of } \\
\text { competences before the lecturer enters } \\
\text { the subject matter her-/ himself }\end{array}$ \\
\hline
\end{tabular}




\section{Outlook}

Beside those improvement measures, the further creation of assignments and new Learning Lab streams is pushed forwardly via the described community of lecturers. Hereby, on the one hand the professional scope is supposed to be widened, and on the other hand assignments with a focus on special topics, e.g. the construction of tablets or IoT applications, should also to be developed. Furthermore, first mutual projects between lecturers arise from the community as well. In addition, extensive accompanying research for quality assurance and measuring regarding the digital competencies is being developed.

\section{References}

Arnold, R. \& Erpenbeck, J. (2014). Wissen ist keine Kompetenz. Dialoge zur Kompetenzreifung. Schneider Verlag: Hohengehren.

Blikstein, P. (2013). Digital fabrication and 'making' in education: The democratization of invention. In J. Walter-Hermann \& C. Büching (Eds.), FabLabs: Of machines, makers and inventors (pp. 203-222). Bielefeld: Transcript Publisher.

Borthick, A. F., Jones, D. R., \& Wakai, S. (2003). Designing learning experiences within learners' zones of proximal development (ZPDs): Enabling collaborative learning onsite and online. Journal of Information Systems, 17(1), 107-134.

Knowles, M. (1975). Self-directed learning: A guide for learners and teachers. New York. Association Press.

Kreulich, K. \& Dellmann, F. (2016) Digitalisierung: Strategische Entwicklung einer kompetenzorientierten Lehre für die digitale Gesellschaft und Arbeitswelt, Fachhochschule Münster University of Applied Sciences: Berlin.

Schüßler, I. (2008). Reflexives Lernen in der Erwachsenenbildung - zwischen Irritation und Kohärenz. Bildungsforschung, 5 (2). Accessable at: https://uhh.de/k9dmq [11.11.2016].

Siebert, H. (2009). Selbstgesteuertes Lernen und Lernberatung. Konstruktivistische Perspektiven. ZIEL Verlag: Augsburg. 